\title{
GROUNDED THEORY-BASED SUBJECTIVE EVALUATION OF TRADITIONAL CHINESE
} PERFORMANCE BUILDINGS

\author{
Jiaxing Zhu ${ }^{\text {a,b }}$, Jian Kang ${ }^{\mathrm{acc},}$, Hui Ma ${ }^{\mathrm{a}}$, Chao Wang ${ }^{\mathrm{a}}$ \\ ${ }^{\text {a }}$ School of Architecture, Tianjin University, Tianjin 300072, China \\ ${ }^{\mathrm{b}}$ China Conservatory of Music, Beijing 100101, China \\ ${ }^{\mathrm{c}}$ Institute for Environmental Design and Engineering, The Bartlett, University College London, UK
}

\section{Abstract:}

Traditional Chinese performance buildings and performing arts are different from those in the west. However, sound quality evaluation factors for western halls have been used in traditional Chinese performance buildings for a long time. In this study, grounded theory was used to establish a sound quality evaluation system for traditional Chinese performance buildings. The subjective evaluation system for a traditional Chinese performance building was divided into the following six aspects: loudness dominant (loudness, definition, loudness balance, stage support (overall), and spaciousness); frequency dominant (brightness and fullness); reflected sound dominant (crispness, richness, harshness, and fusion); direction dominant (envelopment and directivity); quietness; and cultural cognition. The evaluation dimensions of western and traditional Chinese performance buildings were compared. In the Chinese evaluation system, the preference for loudness and brightness was higher than that in the western system. Moreover, crispness, harshness, and cultural cognition were not common in the western evaluation system, whereas envelopment and directivity were rarely mentioned in traditional Chinese evaluation system. Finally, the reasons for the differences between the two evaluation systems were analysed according to the architectural form, performance content, and culture. Envelopment, directivity, and quietness were found to be related to the differences in the architectural form and structure. The preference for brightness, crispness, and definition may be related to the form of performance. The 'competitiveness' and 'renao' (jollification) in traditional Chinese opera performances, as well as aesthetic pursuits had significant effects on the cultural differences.

Keywords: Chinese performance building; sound quality subjective evaluation; grounded theory;

Chinese-western differences

2020 Applied Acoustics

Article history: Received 8 March 2020; Received in revised form 6 May 2020 ; Accepted 8 May 2020 


\section{Introduction}

Traditional Chinese operas, ancient Greek tragedies, and Indian Kutiyattam performances are known as three exemplary types of ancient dramas. There are numerous differences between traditional Chinese operas and western dramas in terms of performance. First, a Chinese opera is a comprehensive performance that includes 'chang' (singing), 'nian' (dialogue), 'Zuo' (acting), and 'da' (acrobatics). Second, because the performance is not restricted to the stage, the time and space of the performance are not limited; therefore, virtual performance reflects reality. Third, stylisation is adopted in the performance [1]. These characteristics of traditional Chinese operas are quite different from those of western performances. As another example, the abundance of performance forms results in an even proportion of music, lyrics, dances, and performances. Artistic performance is not limited to the stage in traditional Chinese operas; therefore, performances are commonly held in outdoor spaces.

Additionally, owing to the performance characteristics, traditional Chinese performance buildings are considerably different from those in the west. The most important characteristic of a traditional Chinese performance space is its semi-open area. The traditional semi-open stage is valuable for folk or intellectual assemblies, although large enclosed theatres have become common in China.

Research on the sound quality of performance buildings in western studies has typically been focused on the sound quality of concert halls. In previous studies, researchers mainly investigated objective parameters such as the loudness and reverberation time. With the development of psychoacoustic theory, the importance of subjective auditory perception has gained increasing attention. Owing to the limitations of recording technology and experimental methods, early subjective research on sound quality was mainly conducted in the form of interviews and subsequent analysis and summarising of the results.

For example, in the early research of Beranek [2], the subjective auditory perceptions of conductors, musicians, and music critics related to the concert hall were studied through interviews, and the subjective parameters were classified as intimacy, reverberation, loudness, warmth, and envelopment. In the 1960s, dummy head recording technology was applied in acoustic research of concert halls $[3,4]$. By using dummy heads for live recordings in concert halls, researchers were able to play back the sounds of different concert halls in the laboratory and perform subjective auditory investigations using the same subjects. This method improved cost and time efficiencies (i.e., time and energy were not wasted travelling among concert halls) and addressed the problems caused by limited auditory memory. Therefore, research on the subjective evaluation of sound quality in concert halls began to advance rapidly in the late 20 th century.

A 1971 study by Hawkes and Douglas [5] marked the beginning of systematic studies on the 
subjective evaluation of the sound quality of concert halls. They used the factor analysis method, which is a very mature tool in the field of experimental psychology, to study the sound quality. In the study, subjects completed questionnaires containing 16 semantic difference scales, and factor analysis was performed. The results demonstrated that the sound quality could be reduced to the following five orthogonal dimensions: reverberation, balance and fusion, intimacy, definition, and brightness. Barron [3] subsequently incorporated two additional dimensions into the traditional dimensions of definition, reverberation, envelopment, intimacy, and loudness; specifically, one dimension was added to evaluate the balance of sound quality and the other was used to judge the 'overall acoustic impression' of the hall. In the book Concert Halls and Opera Houses, published in 2003, Beranek [6] summarised 30 years of research and categorised the subjective auditory attributes of a concert hall as fullness, intimacy, spaciousness, timbre, envelopment, overall, and dynamic range. In previous studies, in order to obtain more accurate data, only professional users of traditional halls were selected as respondents. For example, Farina asked musicians, musicologists, and music critics to do the subjective evaluation in his study, while conductors were recruited to be the evaluators in Hidaka's research[7,8]. In recent years, with the continual progress made in terms of research methods, the evaluation differences among varying groups and individuals have gradually attracted attention. For example, the subjects selected for previous experimental studies have mainly been experts who were sensitive to sound, whereas few studies have employed non-experts to evaluate sound quality. Galiana et al. [9] took note of this problem and studied the differences between expert and non-expert sound quality evaluations. The results indicated that the non-expert group placed greater emphasis on the following five aspects: fidelity and quality, power, intimacy, reverberation, and sound defects. The expert group paid more attention to the balance and pitch quality, intimacy, wide dynamic range, power, brightness, softness, enhanced bass, and sounds without defects. According to the results, in addition to evaluating the positive aspects of the sound quality, the expert group was also concerned with the sound defects in space. The non-expert group placed greater emphasis on the overall evaluation, whereas the expert group could distinguish the dimensions more accurately.

In recent years, people had begun to realize that enjoying music in a concert hall is a multi-sensory experience. In addition to hearing, senses such as vision and temperature may affect people's perception. The research on audio-visual interaction have been a research focus. In most studies, the respondents were asked to give their subjective evaluation under audio-visual conditions [10]. Cabrera conducted the visual experiment and auditory experiment in the same environment [11] and the results showed that distance was also important for both vision and hearing, and some attributes of spatial impression diverged between the senses. Tokunaga conducted a similar experiment, which showed 
significant relationships between the "reverberance" and "ceiling height", and between "loudness" and "distance perspective"[12]. Unlike other studies, Platz used meta-analysis to study the audio-visual relationship, and it turned out that visual component was an important factor in the communication of meaning [13]. In recent years, the specific features of sound sources in the concert halls were studied, including loudness[14], dynamic of the orchestra[15,16] and stage acoustics[17,18].

Furthermore, in traditional studies, researchers have mainly used multiple factor analysis (MFA), hierarchical MFA, principal component analysis, and other methods. However, in such approaches, the perception differences among individuals are often ignored. Therefore, in recent studies, an individual sensory assessment method using individual vocabulary profiling (IVP) has been applied to distinguish the perception differences of individuals more accurately. For example, Lokki et al. [19] used the IVP method to study the timbre of nine concert halls in Finland and eventually defined the following evaluation dimensions: definition, size of the space, envelopment, width of sound (bass), loudness, distance, ungrouped, balance, and openness.

The most representative performance building in China is the Xitai. The earliest prototype of the Xitai can be traced back to the dance kiosk in the Song dynasty, around the 10th century. With the changes in the contents of Chinese folk performances, the performance building forms also evolved. The early stage of the dance kiosk gradually developed into the Xitai form (as shown in the Fig. 1) [20]. With the gradual increase in the understanding of western architectural acoustics in China, research on traditional Chinese performance architectural acoustics was also initiated. Wang $[21,22]$ performed detailed measurements of the RT, C80, G, and ST early in the traditional Chinese Xitai from the perspective of architectural acoustics and analysed different parameters of the architectural acoustics in various forms of the traditional Chinese Xitai. In recent years, researchers have focused on measuring the acoustic parameters of the Xitai in different forms or on using simulation technology to study the sound field of Xitai. The current research on traditional Chinese performance buildings is mainly based on the measurement of objective parameters and sound field simulations, and few studies have been conducted on subjective evaluations of sound quality. Throughout the lengthy process of historical development, traditional Chinese performance buildings and performance forms have been evolving continually into independent art forms, along with corresponding evaluation systems, together with Chinese aesthetic values. However, the western evaluation system has generally been used in research on traditional Chinese performance buildings, which inevitably leads to deviations. 


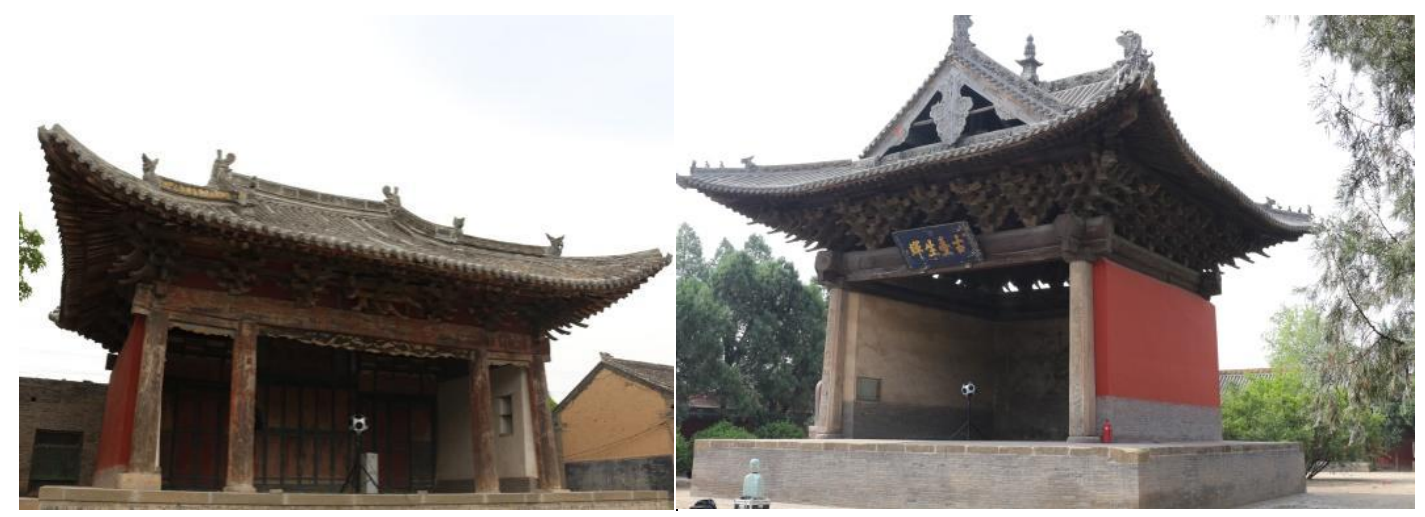

(a)

(b)

Fig. 1 Photographs of traditional Chinese Xitai, (a) Xitai of the Ming dynasty, (b) Xitai of the Yuan dynasty

Therefore, it is important to establish a sound quality evaluation system for traditional Chinese performance buildings. In this study, we attempted to develop a sound quality evaluation system for traditional Chinese performance buildings by using grounded theory and to determine appropriate evaluation dimensions for the sound quality of traditional Chinese performance buildings. Moreover, we compared the sound quality evaluation system for traditional Chinese performance buildings with that for western architecture and discuss the differences between the two systems in terms of the evaluation dimensions. Finally, by investigating the differences between the two evaluation systems further, we identified potential reasons for these differences.

\section{Methods and process}

At present, no mature theoretical framework is available for the construction of a sound quality evaluation system for traditional Chinese performance buildings. Therefore, it was necessary to complete the theoretical construction from scratch during the research process. For this reason, grounded theory was used to perform the theoretical analysis.

Grounded theory is a qualitative research method proposed by Glaser and Strauss in 1967 [23]; it allows for substantial data and research insights for consideration and is useful for elucidating the underlying mechanisms of certain phenomena. Therefore, it is well suited for the establishment of theoretical frameworks in initial research [23]. In the field of acoustics, grounded theory has been adopted in soundscape, environmental noise perception, and health research [24-28]. In the later years of grounded theory, procedural and constructivist schools gradually developed. The difference between these two schools is that a procedural school emphasises the specific programming formula to be followed in the coding process, whereas a constructivist school follows the heuristic principle [29]. In this study, the constructivist school method was used for coding. 
When using grounded theory in the research process, interviewees at different levels should be considered. At the beginning of this study, four groups of professional musicians, amateur musicians, research experts, and amateur audiences were selected as the targets for experimental research, and pre-research procedures were conducted.

When using grounded theory in the research process, it needs detailed and in-depth interview materials, and more attention should be paid to the quality of interviews rather than the quantity. Therefore, in the research process, the number of subjects should be constantly increased until no new content appears (saturation was reached) [30.31]. In this study, we conducted in-depth interviews with 10 subjects and explored the interview contents deeply. After that, the same work was done for the other 3 subjects, and no new content was found, which means saturation was reached.

At the same time, the method of open sampling is adopted in this study, which refers to the selection of research subjects who can provide the maximum coverage of the research problem to conduct interviews [32]. Therefore, different kinds of interviewees should be considered. Before the beginning of this study, four groups of professional musicians, amateur musicians, research experts, and amateur audiences were selected as the targets for experimental research. The pre-research work mainly involved the cognition of sound quality in a semi-open space. It was found that only amateur audiences and amateur musicians could roughly identify differences in sound quality among different spaces. Therefore, in the formal interviews, only research experts and professional musicians were selected as the research targets.

Finally, in this study, 13 respondents were interviewed, of which 10 were musicians who had been performing in traditional Chinese performance buildings for a long time, and three were experts studying traditional Chinese performance art. In this study the ratio of male to female ratio was 9:4, and the age distribution was $27-42$ years old.

\subsection{Research process}

In this study, information was obtained from the respondents via detailed interviews. Each interview was conducted by using unstructured, open-ended questions. The interview time for each participant was approximately 40-60 min. The interview content was mainly focused on the following three aspects. First, the basic background of each participant was investigated to determine his or her understanding of the sound quality of traditional performance buildings and their basic attitudes towards different performance architecture forms and environments. Thereafter, descriptions of the characteristics of the sound sources in the performance buildings were obtained, mainly to understand their degree of sensitivity to sound and their ability to distinguish different sound tones in various 
environments. The final part focused on the sense of sound in a traditional space, which also provided insight into the perception dimensions and dimension relations, as well as the importance of the different dimensions. The types of questions used are listed in Table 1.

Table 1: Specific questions

\begin{tabular}{|c|c|c|}
\hline Category & Question details & Question aims \\
\hline \multirow{4}{*}{ Background } & Name; age & Basic information \\
\hline & $\begin{array}{l}\text { How often do you go to see live Chinese opera } \\
\text { performances? }\end{array}$ & $\begin{array}{l}\text { Familiarity with } \\
\text { performance }\end{array}$ \\
\hline & $\begin{array}{l}\text { Have you ever performed/watched a performance in a } \\
\text { semi-open space? }\end{array}$ & $\begin{array}{l}\text { Familiarity } \\
\text { performance space }\end{array}$ \\
\hline & $\begin{array}{l}\text { Have you ever performed/watched a performance in a } \\
\text { semi-open space where sound amplification was not used } \\
\text { during the performance? }\end{array}$ & $\begin{array}{l}\text { Familiarity with } \\
\text { performance environment }\end{array}$ \\
\hline \multirow[b]{2}{*}{$\begin{array}{l}\text { Features of } \\
\text { the sound } \\
\text { source }\end{array}$} & $\begin{array}{l}\text { Which types of sounds can you hear in a semi-open space } \\
\text { in addition to normal performance sounds? }\end{array}$ & $\begin{array}{l}\text { Sensitivity to sound } \\
\text { sources }\end{array}$ \\
\hline & $\begin{array}{l}\text { Can you describe the characteristics of the sound while } \\
\text { watching/performing in a semi-open space? } \\
\text { Can you distinguish the different sounds clearly while } \\
\text { watching/performing in a semi-open space? }\end{array}$ & $\begin{array}{l}\text { Identification of timbre } \\
\text { from different sound } \\
\text { sources }\end{array}$ \\
\hline \multirow{4}{*}{ Sense } & $\begin{array}{l}\text { What is your sense when you listen to music in a } \\
\text { semi-open space? } \\
\text { Could you share with me any interesting story about } \\
\text { listening to music in a semi-open space? }\end{array}$ & $\begin{array}{l}\text { Overall feel of semi-open } \\
\text { space sound quality }\end{array}$ \\
\hline & $\begin{array}{l}\text { What impresses you the most about the sound when you } \\
\text { listen to music in a semi-open space? } \\
\text { What is the most satisfying aspect about the sound when } \\
\text { you listen to music in a semi-open space? }\end{array}$ & $\begin{array}{l}\text { Most concerned dimension } \\
\text { of sound quality in } \\
\text { semi-open space }\end{array}$ \\
\hline & $\begin{array}{l}\text { How do you evaluate the sound quality of space as } \\
\text { good/bad? According to which aspects do you evaluate? } \\
\text { Please elaborate as much as you can. }\end{array}$ & $\begin{array}{l}\text { Dimensions of sound } \\
\text { Quality evaluation in } \\
\text { semi-open space }\end{array}$ \\
\hline & $\begin{array}{l}\text { What do you think about the difference between } \\
\text { semi-open and enclosed space in sound? }\end{array}$ & $\begin{array}{l}\text { Differences among types } \\
\text { of spaces }\end{array}$ \\
\hline
\end{tabular}




\subsection{Coding results}

The interview records were analysed by using the grounded theory method with the following specific steps.

1. Open coding: the text of all the interview contents was sorted, and key phrases were extracted according to subjective understanding for coding.

2. Merge key phrases: using subjective understanding, the extracted key phrases with the same meanings were merged.

3. Simplify key phrases: the key phrases were summarised as keywords.

4. Extract concepts: the different phrases and relationships were compared to summarise the concepts at different levels.

5. Axial coding: through continuous comparison, the relationships among the different concepts were eventually divided into different categories.

6. Determine subcategories: the positive and negative dimensions were determined under different classifications.

7. Determine category relationships: the relationships among different categories were determined.

8. Establishment of theory: the theory of the sound quality evaluation was established based on a semi-open viewing space.

The data were analysed according to the process mentioned above. At least 140 labelling data points (a1) were obtained, along with 36 conceptualising data points (aa1), 31 categorising data points (A1), and six categories (AA1). The specific analysis results are presented in Table 2.

\section{Sound quality evaluation of traditional Chinese performance buildings}

According to the data, the subjective evaluation system of traditional Chinese performance buildings can be divided into the following six aspects: loudness dominant (loudness, definition, loudness balance, stage support (overall), and spaciousness); frequency dominant (brightness and fullness); reflected sound dominant (crispness, richness, harshness, and fusion); direction dominant (envelopment and directivity); quietness; and cultural cognition (the sound is not natural/not traditional). The details of the categories are presented in Table 3. 
Table 2: Coding process

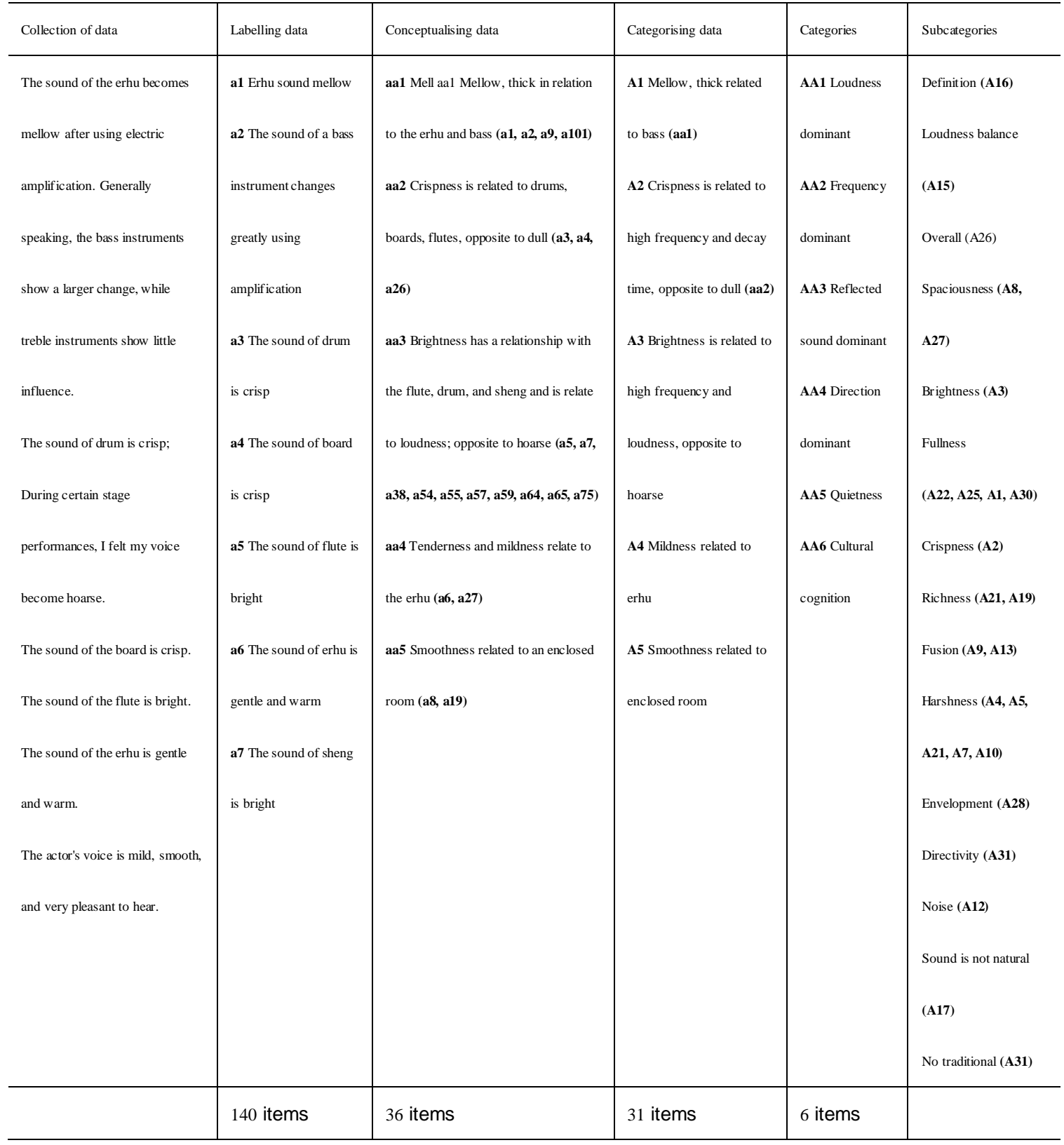

Table 3: Evaluation dimensions of traditional Chinese performance buildings

\begin{tabular}{l|l}
\hline Category & Subcategories \\
\hline Loudness dominant & Loudness, definition, loudness balance, stage support (overall), and spaciousness \\
Frequency dominant & Brightness and fullness \\
Reflected sound dominant & Crispness, richness, harshness, and fusion \\
Direction dominant & Envelopment and directivity \\
Quietness & Noise \\
Cultural cognition & Sound is not natural/not traditional \\
\hline
\end{tabular}




\subsection{Loudness dominant}

Loudness was the most frequently mentioned dimension in all the interviews, and this feature was also considered to be the most important dimension. According to the data arrangement, four main aspects (subcategories) are related to loudness, namely, the definition (A16), loudness balance (A15), stage support (overall) (A26), and spaciousness (A8).

Definition: The definition was repeatedly mentioned in the interviews. The definition is mainly related to the loudness heard by the audience. For example, if there is a certain distance between the stage and audience, the singing and music will be inaudible (a21). Chinese traditional opera does not emphasise the melody alone; it is important to hear the lyrics clearly, rather than only the melody (a85). Moreover, it was mentioned in the interviews that the definition is related to the decay rate; for example, 'Not only is the inaudibility related to the loudness, but it is not clear when the words are sung closely' (a30). Certain instruments have long decay times (such as small gongs) and are inaudible in enclosed spaces but can be heard clearly in open spaces (a42).

Loudness balance: This aspect generally refers to the balance between different parts when listening to a performance so that the accompaniment is not overly loud compared to the voices and one part is not overly loud compared to the other parts. For example, in an open space, the voice of an actor can be extremely soft and difficult to hear over the instruments (a20). Furthermore, when performing in the small theatre of our department, the balance between the voice of the actor and the sound of the instruments was very good, and the two did not affect one another (a76).

Stage support (overall): This item mainly refers to a player who can hear his or her voice and other parts on stage. In the interviews, the actors placed high value on being able to hear their voices on the stage. If musicians can hear their voices, they can perform better on stage (a91). For example, electric sound amplification is very important in opera performances, as it can enlarge the sound and transmit it to all the audience members. It is also very important for an actor to hear his or her voice when singing (a125).

Spaciousness: This feature generally describes the feeling of distance and sense of the size of the space when performing. The interview data mainly reflected the perception of loudness. For example, 'if the space feels small, the voice will be louder, and the sound will be better' (a15). It is preferable to allow people to feel more intimate during the performance and not to have a sense of distance (a79). Moreover, it was found in the interview that spaciousness is also related to the reverberation time. For example, with many people in a large space, the sound will be absorbed, whereas with a few people (approximately 50) in a small theatre, the effect is still good (a43). 


\subsection{Frequency dominant}

According to the collected materials, two dimensions are closely related to the frequency and mainly describe the perception of the timbre of a musical instrument in space, namely, the sound brightness (A3) and sound fullness (A22, A25, A1, and A30).

Brightness: The brightness of sound generally involves two aspects, the first of which describes the high frequency of the sound. For example, the sounds of a bamboo flute and sheng are better if they are brighter (A5 and A8). Second, the brightness is related to the loudness. For example, 'if the performance space is very small, the sound will be very bright' and 'The sound is brighter when performing indoors' (A49 and A52). Thus, it can be concluded that the perception of brightness is determined by both the frequency and loudness.

Fullness: The fullness mainly describes a sound that has thickness; that is, the sound has energy in each frequency band, and its opposites are emptiness, flatness, and thinness. In the interviews, the participants mentioned (for certain spatial sounds) that the sound was flat, mixed, and not full, as when listening to a cassette recorder with bad quality (a83). Sound should be layered, and high and low frequencies should be balanced (a98).

\subsection{Reflected sound dominant}

According to the arrangement of the materials, the perceptions of four dimensions are related to the main characteristics of reflected sound, namely, crispness (A2), richness (A21 and A19), fusion (A9 and A13), and harshness (A4, A5, A21, A7, and A10).

Crispness is generally used to evaluate the short decay time of musical instruments in space, and the opposite of crispness is dullness. For example, the sound of the bamboo flute is natural, pleasant, crisp, and bright (a26), whereas the sound of the 'bangu' (a type of small drum) is crisp (a3). However, in the analysis, it was found that the word 'crisp' is related to the frequency in addition to the decay time; for example, the sound is more transparent and brighter, instead of dull (a36). Therefore, it can be concluded that the sound decay time and frequency are the main factors affecting the crispness.

Richness mainly describes the plumpness and mellowness of the sound, and its opposites are dryness, shrivelling, and hoarseness. For example, the tone of the erhu should be very mellow; however, in certain theatre performances, the voice will be very shrivelled (a74), and when entering a recording room, it will be very dry, bringing out the essence of the voice (a34). For example, 'During certain stage performances, I felt my voice become hoarse' (a57). It can be concluded that the fullness is related to the reflected sound of the space. 
Harshness (roughness) describes the roughness of the sound, as opposed to cleanness. According to the analysis of the interview contents, harshness is mainly determined by two aspects. Sound reflections are a key aspect. For example, if one plays a percussion instrument in an enclosed or relatively enclosed room, it will sound pleasant; meanwhile, if one plays the instrument in a relatively enclosed place, the 'roughness' in sound cannot be heard because of high echo (a32). 'The distance is far away, and when it reaches me, it changes. It is no longer clean and becomes noisy' (a14). Another aspect is related to loudness; for example, 'for some audiences, the sound of drums is loud and rough' (a24).

Fusion generally describes the unity of the sound, which contrasts with dispersion/divergence. It was mentioned in the interviews that sound fusion is mostly related to multiple reflections. For example, 'the sound of the outdoor performance is diverging' (a13) and 'In the orchestra pit or in the legs, the sound will be different; in the orchestra pit, the sound will blend together' (a17). Another response was that 'the instruments do not blend well enough, like disappearing into the air' (a68). It can be observed that fusion is related to the presence of multiple reflective surfaces, such as the orchestra pit and legs, which mainly describes the sound as unitive.

\subsection{Direction dominant}

In the collected interview contents, two dimensions were found to be related to the sense of direction, namely, envelopment (A28) and directivity (A31). In the collected materials, both dimensions were mentioned when discussing the sound quality of modern enclosed theatres, but not when talking about traditional open spaces.

The envelopment mainly emphasises that the sound source is not singular. For example, 'envelopment' is more obvious in the Chang' An theatre; there is no such feeling on the traditional stage' (a84). The sense of position emphasises that sound can be transmitted from different directions. As mentioned in the interview, 'it sounds better from different directions (front and rear, up and down, left and right)' (a97).

\subsection{Quietness and cultural cognition}

Quietness: The descriptions of a quiet environment were relatively uniform, and all the respondents believed that a quiet environment is more conducive to performance. It was also mentioned that the sound quality will be affected in a noisy environment: 'If it is noisy, it is not good' (a16, a50, a109, and a115). As mentioned in the interviews, the most influential noises in a semi-open 
space are due to people talking, children crying, wind, and the current noise of the amplification equipment.

Cultural cognition: When the interviewees mentioned the sound quality of traditional Chinese performance buildings, certain aspects were not actually related to the sound quality, but rather to cultural identity. For example, several interviewees suggested that it would be discordant to perform in a traditional semi-open space with electronic musical instruments or sound-amplifying systems (a111). Furthermore, certain respondents argued that sound is more natural without amplification (a22).

\section{Comparison of sound quality evaluations for Chinese and western performance buildings}

When comparing the above-mentioned evaluation dimensions of the sound quality of traditional Chinese performance architecture with those in the west, several differences were identified, as indicated in Table 4.

Table 4: Comparison of evaluation dimensions of Chinese and western systems

\begin{tabular}{|c|c|c|}
\hline Western evaluation system & $\begin{array}{c}\text { Traditional Chinese evaluation } \\
\text { system }\end{array}$ & Relationship \\
\hline Fullness & Fullness & Similar \\
\hline Fusion & Fusion & Similar \\
\hline Balance & Loudness balance & Similar \\
\hline Balance & Richness & Similar \\
\hline Definition & Definition & Similar \\
\hline Intimacy & Spaciousness & Similar \\
\hline Warmth & Brightness & Slightly different \\
\hline Loudness & Loudness & Slightly different \\
\hline Quietness & Quietness & Slightly different \\
\hline Clarity & Null & Different \\
\hline Null & Crispness & Different \\
\hline Null & Harshness & Different \\
\hline Envelopment & Null & Different \\
\hline Directivity & Null & Different \\
\hline Null & Cultural cognition & Different \\
\hline
\end{tabular}


In the two evaluation systems, fullness, fusion, loudness balance, richness, definition, and spaciousness are similar. There are slightly different perceptions of warmth, loudness, and quietness. Meanwhile, there are significant differences in clarity, crispness, harshness, envelopment, directivity, and cultural cognition. Explanations are provided in the following sections.

\subsection{Similar and slightly different dimensions}

Among the similar dimensions in the Chinese and western evaluations, the cognitions of fullness, fusion, and loudness balance are relatively consistent, whereas those of richness, loudness, definition, and intimacy are slightly different. Therefore, the dimensions of fullness, fusion, and loudness balance are not discussed in this paper, and the remaining dimensions can be analysed as follows.

Richness: In the Chinese traditional evaluation system, richness mainly describes the mellowness of the sound, which is consistent with balance in the western evaluation system. Sound has energy in all frequency bands. However, in the western evaluation system, balance usually has two meanings; one refers to the richness, and the other refers to the balance between the various parts of the band, i.e. the loudness balance.

Loudness: In the western evaluation system, loudness is an important dimension. In many studies, the contribution of loudness to the sound quality ranks first or third. However, it can be observed from the evaluation results of traditional performance spaces in China that the preference for loudness is much higher than that in the west. This finding indicates that loudness plays an extremely important role in the traditional evaluation system of China. In certain interviews in this study, the interviewees even believed the best performance volume to be slightly ear-piercing (a78), which is unthinkable in the western evaluation system. In several western studies, it has been mentioned that the preference for sound can be divided into the following two categories: the preference for loudness and for clarity. However, ear-piercing sound is not preferred. Tereping found that in live listening environments, the preferred sound level for the genre classical music, smaller jazz and big band groups is about $73-85 \mathrm{~dB}$ (A), and the evaluation on overall pleasantness decreases somewhat when sound levels are either too high or too low [33]. Similar results have been obtained by other study [34]. Therefore, the preference for high loudness in the traditional Chinese evaluation system is higher than that in the west. A hypothesis was proposed by S. Dance [35]: 'musicians have learned to control their Stapedius Reflex, to protect themselves from their instrument's noise'. This concept may explain why musicians can tolerate high loudness, but it does not explain the preference for high loudness.

Definition: In the western evaluation system, the definition is an important evaluation dimension, which is also reflected in the traditional Chinese evaluation system. The importance of definition was 
mentioned in all the interviews. However, several differences exist. In the western evaluation dimensions, definition is generally divided into two categories, namely, one for lyrics, known as definition, and the other for music, known as clarity [36]. No distinction is made in the Chinese evaluation system. The definitions of lyrics and music can be evaluated simultaneously, which is probably related to the large proportion of opera lyrics in traditional Chinese performance forms.

Spaciousness: Certain differences exist between the Chinese and western evaluations of spaciousness. In the west, the evaluation of spaciousness mainly focuses on the sound-source direction, which generally includes the following two aspects: the apparent source width and listener envelopment [6]. In the study of the traditional Chinese evaluation, spaciousness is the intuitive sense of the size of the performance space and distance from the sound source. The content of the evaluation is more inclined towards intimacy in the western evaluation dimension.

Quietness: To describe the noise of the space, this dimension is not typically evaluated separately in the western evaluation system, which may be because western performance buildings are closed and the background noise is typically low. Therefore, the influence of background noise on the sound quality is often ignored in the evaluation. However, as traditional Chinese performance buildings are open or semi-open, the background noise affects the sound quality and cannot be ignored, which is why quietness was frequently mentioned in the interviews.

Brightness: In the traditional Chinese evaluation, a bright timbre is preferred, and the study demonstrated that this dimension is correlated with both the frequency and loudness. In the western evaluation dimensions, brilliance is often used to express a similar meaning. However, the results of numerous studies have demonstrated that brilliance is related to the reverberation time of a high frequency, but not to loudness. Moreover, brilliance is rarely mentioned in the literature, whereas warmth and business are often used instead to evaluate sound quality. This characteristic indicates that, in the western evaluation system, full bass is believed to be good, whereas in the traditional Chinese evaluation system, there is a preference for high-frequency sound. Furthermore, in the Chinese evaluation system, brightness has the following two meanings: high frequency and high loudness.

\subsection{Different dimensions}

Among all the evaluation dimensions, the crispness, noise, clarity, envelopment, directivity, and some aspects of cultural cognition are quite different from those in the western evaluation system, as described below.

Crispness: In the traditional Chinese evaluation system, crispness is mainly related to the sound decay and high frequency. It is generally used to describe the timbre of percussion and wind 
instruments, as opposed to the dullness of sound. In the western evaluation system, a similar evaluation dimension does not exist.

Harshness: Like crispness, harshness is not mentioned in the western evaluation system. In the traditional Chinese evaluation system, harshness is related to the spatial reflection and loudness and is relative to the sound cleanliness.

Clarity: In the western evaluation system, the discrimination of music is defined as clarity, but in the traditional Chinese evaluation system, a similar evaluation dimension does not exist.

Envelopment and directivity are generally summarised as spaciousness in the western evaluation dimensions. These correspond to the width and surrounding degree of the sound source, respectively. However, they seldom appear in the traditional Chinese evaluation system. These two dimensions are typically used to describe the sound quality of modern enclosed theatres. In this study, the interviewees mentioned that this type of feeling does not exist in a space like the traditional Chinese stage.

Cultural dimensions: In addition to the above dimensions, certain dimensions that are unrelated to sound quality but are related to cultural identity have also appeared in traditional Chinese evaluations, but these have never been identified in the western evaluation system.

\section{Discussion: Possible reasons for differences between Chinese and western performance buildings}

Traditional performance buildings in China are mainly semi-open, whereas western performance buildings are generally enclosed theatres and concert halls. Among the differences between the two evaluation systems, envelopment, directivity, and quietness may be related to the architectural differences between China and the west. For example, envelopment and directivity play obvious roles in closed spaces but have less influence on the audience in open and semi-open spaces. Therefore, in semi-open Chinese performance buildings, these two items are not generally evaluated. The same can be said for quietness; in early studies in the west, because the research objects were mainly professional concert halls with good sound quality, few evaluations were conducted on sound defects and background noise. In later studies with various research objects, noise and sound defects began to appear gradually in the evaluation system. However, in the traditional Chinese evaluation system, the quietness of the performance space is an extremely important dimension, which is probably also related to the semi-open form. It is worth mentioning that there are usually 'brackets' in traditional Chinese buildings (as shown in the Fig. 2), which are typical scattering surfaces and provide structural support. Jeon et al. [37] proposed that scattering surfaces changed the arrival time of the reflections, and the sound sources affected by scattering surfaces were preferred. In his another study, it was proposed that 
the Np (number of peaks) formed by the scattering surface had a certain influence on the subjective preference of the audience [38]. Therefore, brackets may play a role in improving sound quality of traditional Chinese performance architecture.

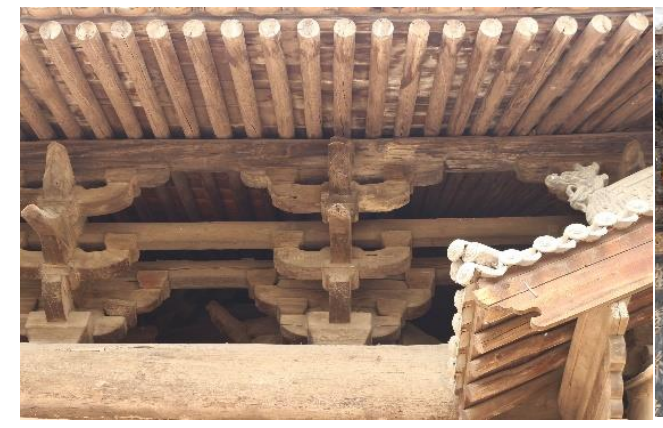

(a)

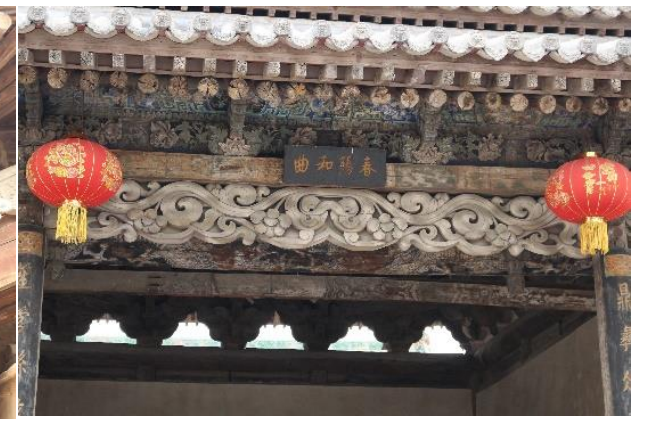

(b)

Fig. 2 Photographs of 'brackets' of the traditional Chinese buildings, (a) 'brackets' of the Yuan dynasty, (b) 'brackets' of the Ming dynasty

Among all the differences, the differences in brightness, crispness, and clarity are likely related to the content differences between Chinese and western performances. The western evaluation system tends towards warmth and blandness, with little consideration of the aspects of the opposites (for example, brightness and crispness). This tendency may be associated with the sealing of western performance buildings but may also be related to the instruments; for example, numerous bass instruments (such as cello and double bass) appear in western orchestras, but it is almost impossible to find similar traditional Chinese instruments. In contrast, high-pitched, fast-decay instruments are common in traditional Chinese opera accompaniments. Furthermore, Chinese opera is a type of integrated art form that incorporates music, drama, dance, and performance, whereas the art forms of language (drama), music, and dance (dance drama) were considered separately in early western evaluations. Therefore, in the western evaluation system, definition and clarity are refined, whereas this refinement does not appear in the traditional Chinese evaluation system.

In addition to the above dimensions, the preferences for loudness, harshness, and other cultural aspects in the traditional Chinese evaluation system are related to the aesthetics of Chinese theatrical performances. Mao [39] compared the Chinese equal-loudness level contours (ELLCs) with the data from the 2003 revision of ISO 226. The results show that Chinese ELLCs are about $3 \mathrm{~dB}$ below the ISO standard for all frequency less than $630 \mathrm{~Hz}$. Therefore, it can be judged that Chinese people perceive loudness at low frequencies more strongly than indicated by the ISO curve. Thus, it can be inferred that the preference for loudness is likely due to cultural differences. As mentioned in the research of several scholars, traditional Chinese opera exhibits the characteristics of 'competitiveness' 
and 'renao' (jollification) [40,41]. That is, in the traditional Chinese performance environment, different opera performers compete for their art during the performance. To gain an advantage in a performance competition, the performance form is mainly reflected in the interaction with the audience during the performance to create a lively atmosphere. This characteristic of 'competitiveness' may explain the preference for loudness and noise in the traditional Chinese evaluation system. Actors constantly increase the loudness of their performance and add special features (such as harshness) to their timbre to leave deeper impressions on audiences and win competitions. Moreover, in traditional Chinese aesthetics, the cognition of nature and the 'harmony between man and nature' may be related to the conflict of the use of electronic musical instruments or sound-amplifying systems in the cultural cognition dimension [42]. The difference could also be due to language differences [43]. Finally, it would be interesting to explore the different in theatrical origins in difference cultures [44].

\section{Conclusions}

In this study, a sound quality evaluation system for traditional Chinese performance buildings was constructed by using grounded theory. The evaluation dimensions of the sound quality of traditional Chinese performance buildings mainly included the following six aspects: loudness dominant (loudness, definition, loudness balance, stage support (overall), and spaciousness); frequency dominant (brightness and fullness); reflected sound dominant (crispness, richness, harshness, and fusion); direction dominant (envelopment and directivity); quietness; and cultural cognition.

The dimensions identified in this study differed from western evaluation dimensions to varying degrees, which were summarised as similar, slightly different, and different. In the similar and slightly different dimensions, the preferences for loudness and brightness were higher than those in the western evaluation system. Moreover, crispness, harshness, and culture are not common in the western evaluation system, whereas envelopment and directivity are rarely mentioned in traditional Chinese evaluations of the sound quality of performance buildings.

Further, the reasons for the differences between the two sound quality evaluation systems were analysed. The different architectural forms and structures lead to variations in the envelopment, directivity, and quietness. Furthermore, the different sound sources in traditional Chinese opera and musical (opera) performances may be related to the dissimilar preference for brightness and crispness. Culture is also an important factor that causes disparity between the two evaluation systems. The 'competitiveness' and 'renao' (jollification) in Chinese traditional opera performances, as well as the aesthetic pursuit of 'harmony between man and nature' may significantly affect the cultural differences. 
In this study, the subjective evaluation of sound quality in traditional Chinese performance buildings was mainly analysed via qualitative research, which was focused on determining the dimensions of the evaluation systems. Hence, the relationships among different evaluation dimensions could not be obtained. In future research, it will be necessary to conduct subjective evaluation experiments to quantify the relationships among different dimensions to describe the sound quality evaluation system of traditional Chinese performance architecture more thoroughly.

\section{References}

1. H. Li: A comparison of Chinese and western theatrical performance systems. Journal Beijing Second Foreign Language Institute 12 (1995).

2. L. Beranek: Music, Acoustics, and Architecture. John Wiley \& Sons Inc., 1962.

3. M. Barron: Subjective study of British symphony concert halls. Acta Acustica United with Acustica 66(1) (1988) 1-14.

4. S. Paul: Binaural Recording Technology: A Historical Review and Possible Future Developments. Acta Acustica United with Acustica 95 (2009) 767 - 788.

5. R.J. Hawkes, H. Douglas: Subjective acoustic experience in concert auditoria. Architectural Research and Teaching 1(2) (1971) 34-45.

6. L. Beranek: Concert Halls and Opera Houses. Springer Science \& Business Media, 2003.

7. A. Farina, Acoustic quality of theatres: Correlations between experimental measures and subjective evaluations. Applied Acoustics 62(2001)889-916.

8. T. Hidaka, L. L. Beranek: Objective and subjective evaluations of twenty three opera houses in Europe. Japan, and the Americas. Journal of the Acoustical Society of America 107(1) (2000)368-383.

9. M. Galiana, C. Linares, A. Page: Subjective evaluation of music hall acoustics: Response of expert and non-expert users. Building and Environment 58 (2012) 1-13.

10. B. N. J. Postma, B. F. G. Katz: The influence of visual distance on the room-acoustic experience of auralizations. Journal of the Acoustical Society of America142, 3035 (2017).

11. D. Cabrera, A. Nguyen, Y. Ji Choi: Auditory versus visual spatial impression: A study of two auditoria. Proceedings of ICAD 04-Tenth Meeting of the International Conference on Auditory Display. Sydney, Australia 2004.

12. Y. Tokunaga, D. Okuie: Influence of visual information on sound evaluation in auditorium. Journal of the Acoustical Society of America 133 (2013) 34-55.

13. F. Platz, R. Kopiez: When the eye listens: A meta-analysis of how audio-visual presentation enhances the appreciation of music performance. Music Perception 30(1) (2012) 71-83. 
14. S. Wu: Investigation into concert hall loudness evaluation. Applied Acoustics 37(5) (2018) 593-596.

15. T. Lokki, J. Patynen: Objective analysis of the dynamic responsiveness of concert halls. Acoustical Science and Technology 41 (1) (2020) 101250.

16. J. Patynen, T. Lokki: Perception of music dynamics in concert hall acoustics. Journal of the Acoustical Society of America 140 (5) (2016) 3787 - 3798.

17. J. Jeon, R. Seo, H. Jo: Effect of Stage Volume Ratio on Audience Acoustics in Concert Halls. Sustainability 12 (2020) 1370 .

18. H. S. Jang, J. Y. Jeon: Acoustic characterization of on-stage performers in performing spaces. Applied Acoustics 114 (2016) 159 - 170

19. T. Lokki, J. Pätynen, A. Kuusinen, H. Vertanen, S. Tervo: Concert hall acoustics assessment with individually elicited attributes. The Journal of the Acoustical Society of America 130(2) (2011) 835849.

20. B. Liao: History of ancient Chinese theatre. Zhongzhou Ancient Books Publishing House, 1997.

21. J. Wang: A primary study of the acoustics of Chinese traditional theatrical buildings. Technical Acoustics 01 (2002).

22. J. Wang: Acoustics of courtyard spaces. Acta Acustica 32(4) (2007) 289.

23. B.G. Glaser, A.L. Strauss: The Discovery of Grounded Theory: Strategies for Qualitative Research. Chicago, Aldine, 1967.

24. F. Liu, J. Kang: A grounded theory approach to the subjective understanding of urban soundscape in Sheffield. Cities 50 (2016) 28-39.

25. S.H. Park, P.J. Lee, K.S. Yang: Perception and reaction to floor impact noise in apartment buildings: A qualitative approach. Acta Acustica United with Acustica 102 (2016) 902-911.

26. B. Schulte-Fortkamp, A. Fiebig: Soundscape analysis in a residential area: an evaluation of noise and people's mind. Acta Acustica United with Acustica 92 (2006) 875-880.

27. M. Haines, S. Brentnall, S. Stansfeld, E. Klineberg: Qualitative responses of children to environmental noise. Noise \& Health 5 (2003) 19-30.

28. P. Lercher: Environmental noise and health: an integrated research perspective. Environment International 22 (1996)117-129.

29. K.C. Charmaz: Constructing Grounded Theory: A Practical Guide Through Qualitative Analysis. Thousand Oaks, Sage Publications, 2006.

30. H. Pryce, A. Hall, R. Shaw, B. Culhane, S. Swift, J. Straus, B. Claesen: Patient preferences in tinnitus outcomes and treatments: a qualitative study. International Journal of Audiology 57 (10)2018. 
784-790.

31. S. Dobbins, E. Hubbard, A. Flentje, C. D. Rose, H. Leutwyler: Play provides social connection for older adults with serious mental illness: A grounded theory analysis of a 10-week exergame intervention. Aging \& Mental Health. 24 (2018) 596-603.

32. M. Fan, J. Wu: Qualitative Research. Truth \& Wisdom Press. Shanghai People's Publishing House, 2009.

33. A. Tereping: Listener Preference for Concert Sound Levels: Do Louder Performances Sound Better? Journal of the Audio Engineering Society 64 (3) (2016) 138-146.

34. K. R. Kahari, T. Åslund, J. Olsson: Preferred Sound Levels of Portable Music Players and Listening Habits among Adults: A Field Study. Noise \& Health, 13 (50) (2011) 9-15.

35. S. Dance, B. Dymock: Sound exposure of musicians and music induced hearing loss. Euronoise 2015 Conference, Maastricht, 2015.

36. M. Barron: Loudness in concert halls. Acta Acustica United with Acustica 82(Suppl.1) (1996) S21S29.

37. J. Jeon, H. Jang, Y. Kim: Influence of wall scattering on the early fine structures of measured room impulse responses. The Journal of the Acoustical Society of America 137 (3) (2015) 1108-1116.

38. J. Jeon, H. Jo, R. Seo, K. Kwak: Objective and subjective assessment of sound diffuseness in musical venues via computer simulations and a scale model. Building and Environment 173 (2020) 106740.

39. D. Mao, Y. Wang: Equal-loudness level contours of Chinese speakers. Technical Acoustics 26(02) (2007) 273 .

40. Y. Wang: A Study on the Renao of Chinese Traditional Drama. PhD Dissertation, Shanghai Normal University, 2012.

41. Y. Wang: Forms and influence of competing art performances in Rexi. Studies in Culture \& Art 01 (2012).

42. Z. Cai: History of Chinese Musical Aesthetics. People’s Music Publishing House, 2003.

43. J. Kang. Comparison of speech intelligibility between English and Chinese. The Journal of the Acoustical Society of America 1998;103:1213-6. https://doi.org/10.1121/1.421253.

44. K. Chourmouziadou, J. Kang. Acoustic evolution of ancient Greek and Roman theatres. Applied Acoustics 2008;69:514-29. https://doi.org/10.1016/j.apacoust.2006.12.009. 